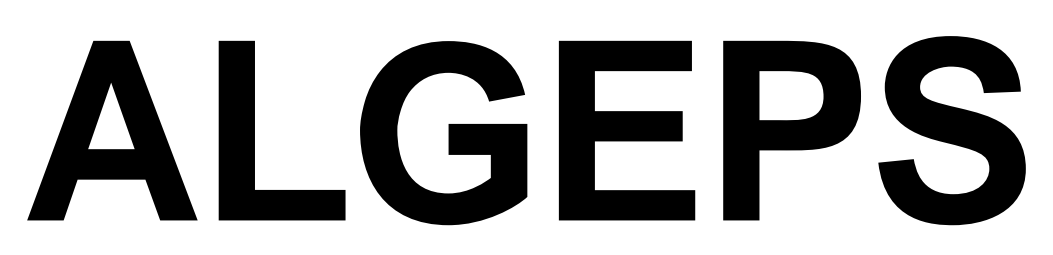

REVISTA DE GEOLOGIA, SĖRIE B no 598 - Agost del 2012

ISSN $1132-7014$

D.L.B. 28.178 - 92

10 pàgines

\begin{abstract}
RECORRIDO DESDE SABIÑÁNIGO A RASPÚN, AL HOSTAL DE ISPIÉS A CALDEARENAS, A BONREPÓS Y A GÉSERA, A TRAVÉS DEL PATRIMONIO GEOLÓGICO Y MINERO DE LAS COMARCA DEL ALTO GÁLLEGO
\end{abstract}

Josep M. Mata-Perelló

Aquest recorregut va ésser experimentat amb docents el dia 1 DE SETEMBRE DEL 2010 


\section{RECORRIDO DESDE SABIÑÁNIGO A RASPÚN, AL HOSTAL DE ISPIÉS A CALDEARENAS, A BONREPÓS Y A GÉSERA, A TRAVÉS DEL PATRIMONIO GEOLÓGICO Y MINERO DE LAS COMARCA DEL ALTO GÁLLEGO}

\section{ADVERTENCIAS PREVIAS}

Como en otros recorridos de RECONOCIMIENTO GEOLÓGICO (o de RECONOCIMIENTO GEOLÓGICO Y MINERO), el recorrido se compondrá de diversas PARADAS. En este caso serán seis.

Por otra parte, habrá que tener en cuenta, en todo momento, especialmente antes de empezar los recorridos de los diferentes tramos, el estado de los caminos y carreteras, por donde transitará el recorrido. Al respecto, cabe decir que prácticamente todos estos tramos se halla en buenas condiciones.

Finalmente, como ya hacemos en otros recorridos similares, queremos decir que hace falta tener un cuidado muy especial en el respeto a la naturaleza, a lo largo de todo el recorrido del itinerario, y también fuera de él.

\section{BREVE INTRODUCCIÓN GEOLÓGICA}

El recorrido de este itinerario, se desarrollará por una de las tres unidades geológicas que constituyen el suelo y el subsuelo de Aragón. Concretamente por el Sistema Pirenaico, Cordillera Pirenaica o simplemente Pirineos; discurriendo íntegramente por el denominado Pirineo Meridional.

Así, a lo largo de todo de todo el recorrido del itinerario, se irán encontrando afloramientos de los materiales del Cenozoico (fundamentalmente del Eoceno y del Oligoceno), que son los que en este lugar forman parte del Pirineo.

\section{BREVE INTRODUCCIÓN GEOGRÁFICA}

El recorrido del presente itinerario se efectuará casi exclusivamente por una comarca aragonesa, la del Alto Gállego. Así, se iniciará en la propia capital comarcal, en la población de Sabiñánigo, para dirigirse luego hacía el Sur, recorriendo parte de su término municipal y del de Caldearenas. Así, en este recorrido, se circulará solamente por los términos municipales de Sabiñánigo y Caldearenas.

Esta comarca, gravita en torno al río Gállego, tributario del Ebro. Este río recoge las aguas de toda la comarca. 


\section{OBJETIVOS GENERALES DE ESTE ITINERARIO}

En este itinerario, los objetivos generales que se han de conseguir, se pueden concretar en los siguientes aspectos:

1.- Estudio y reconocimiento de los materiales cenozoicos (fundamentalmente del Eoceno y del Oligoceno) situados en los Pirineos, que iremos encontrando a lo largo del recorrido del itinerario, entre las inmediaciones de Sabiñánigo, del puerto de Bonrepós y de Gésera.

2.- Estudio y observación de la estructura de los Pirineos, en los tramos concernientes al recorrido.

3.- Visión de algunas de las antiguas explotaciones encontradas a lo largo del recorrido del itinerario. En concreto de diversas explotaciones de grava, situadas en el municipio de Sabiñánigo (en Orna de Gállego).

4.- Observación del impacto producido por las actividades mineras. I de las restauraciones realizadas para paliar este impacto.

5.- Visión de los diferentes lugares directamente relacionados con el Patrimonio Geológico y Minero que iremos encontrando a lo largo del recorrido del presente itinerario.

\section{ANTECEDENTES BIBLIOGRÁFICOS}

En relación con este itinerario, no conocemos ningún antecedente, relativo a otro itinerario que discurra por este lugar. En este sentido, este itinerario ya constituye un antecedente, si no estamos equivocados.

Por otra parte, tenemos otros antecedentes nuestros, en relación a las mineralizaciones presentes en esta zona. Se trata de MATA-PERELLÓ (1987, 1990), dedicados a las mineralizaciones de Aragón y de esta comarca, respectivamente.

En relación con las características del patrimonio geológico citaremos el trabajo publicado por la GADMA (2001), así como el de CARCAVILLA et altri (2006).

Todos estos trabajos se hallaran debidamente relacionados en el apartado de REFERENCIAS BIBLIOGRÁFICAS, que figura al final del presente trabajo

\section{RECORRIDO DEL ITINERARIO}

Indicaremos, a continuación una posibilidad de itinerario, el cual discurriría por diferentes lugares de la comarca anteriormente citada. Así, el recorrido se iniciará en Sabiñánigo (en la comarca del Alto Gállego), discurriendo rápidamente hacía el Sur, hacía Raspún (en la mima comarca), en donde se realizará una parada. 
Luego, el recorrido llegará hasta el Hostal de Ispiés, desde donde se dirigirá a Baragua, con la finalidad de hacer una nueva parada. Tras ello, retornará a la carretera que se dirige a Caldearenas, efectuando una parada en las cercanías de Horna de Gállego, en una antigua gravera. Luego se dirigirá a Caldearenas y desde ahí a la carretera de Bonrepós, efectuándose una parada por las inmediaciones de Serúe. Tras llegar a las cercanías de Bonrepós, convendrá tomar rumbo al Norte, hasta encontrar la carretera que se dirige hacía Boltaña, con la finalidad de llegar hasta las inmediaciones del Molino de Villobás cerca de Gésera, en donde se realizará la última parada de este itinerario.

\section{DESCRIPCIÓN DEL ITINERARIO}

Como de costumbre, estructuraremos el recorrido del itinerario en una serie de PARADAS, que a continuación iremos viendo. En cada una de estas paradas haremos un breve comentario (geológico o mineralógico, según acontezca).

Por otra parte, en cada caso indicaremos (entre paréntesis) la hoja topográfica en donde se halla la parada. Para ello, utilizaremos las hojas del Instituto Geográfico y Catastral de España, publicadas a la escala de 1:50.000. En este caso, solo utilizaremos una hoja, la siguiente: $\mathbf{2 1 0}$ (o de Yebra de Basa).

Así pues, la relación de las paradas que componen el recorrido de este itinerario, son las siguientes:

PARADA 1. CARRETERA A RASPÚN, EL HOG - BACK DE RASPÚN O LAS RALLAS DE RASPÚN, (Raspún, término municipal de Sabiñánigo, comarca del Alto Gállego). (Hoja 210).

El recorrido del presente itinerario geológico lo iniciaremos en la población de Sabiñánigo, la capital de la comarca del Alto Gállego. Desde la misma población, nos convendrá dirigirnos hacía el Sur por la carretera nacional $\mathrm{N}-330$, con la finalidad de llegar hasta el cercano cruce de la carretera de Raspún, tras tomar esta carretera, pasando al otro lado del río Gállego, efectuaremos una parada a unos 0’5 $\mathrm{Km}$ del inicio de la carretera y a unos $3 \mathrm{Km}$ de Sabiñánigo. Cabe decir que desde la carretera $\mathrm{N}-330$, habremos efectuado una hijuela.

En este recorrido, habremos encontrado fundamentalmente afloramientos de los materiales cenozoicos. Estos materiales constituyen en este sector las estructuras del denominado Pirineo Meridional.

En este lugar puede verse una interesante barra de areniscas verticalizadas (un "hog - back"), perfectamente visible. En la zona se conoce a este lugar como las rallas de Raspún (origen probablemente del nombre del pueblo). Cabe decir que el pueblo, situado junto a este murallón, quedaba perfectamente resguardado del viento.

Cabe decir que esta interesante estructura, constituye el flanco septentrional del sinclinorio del Guarga y está formado por unas areniscas calcáreas de origen fluviomarino y edad terciaria. Se trata de materiales que anuncian el paso a condiciones 
sedimentarias netamente continentales, propias del Terciario superior en esta zona del Pirineo. Esta estructura es perfectamente visible desde el río Gállego hasta la propia población, continuando más allá de la misma.

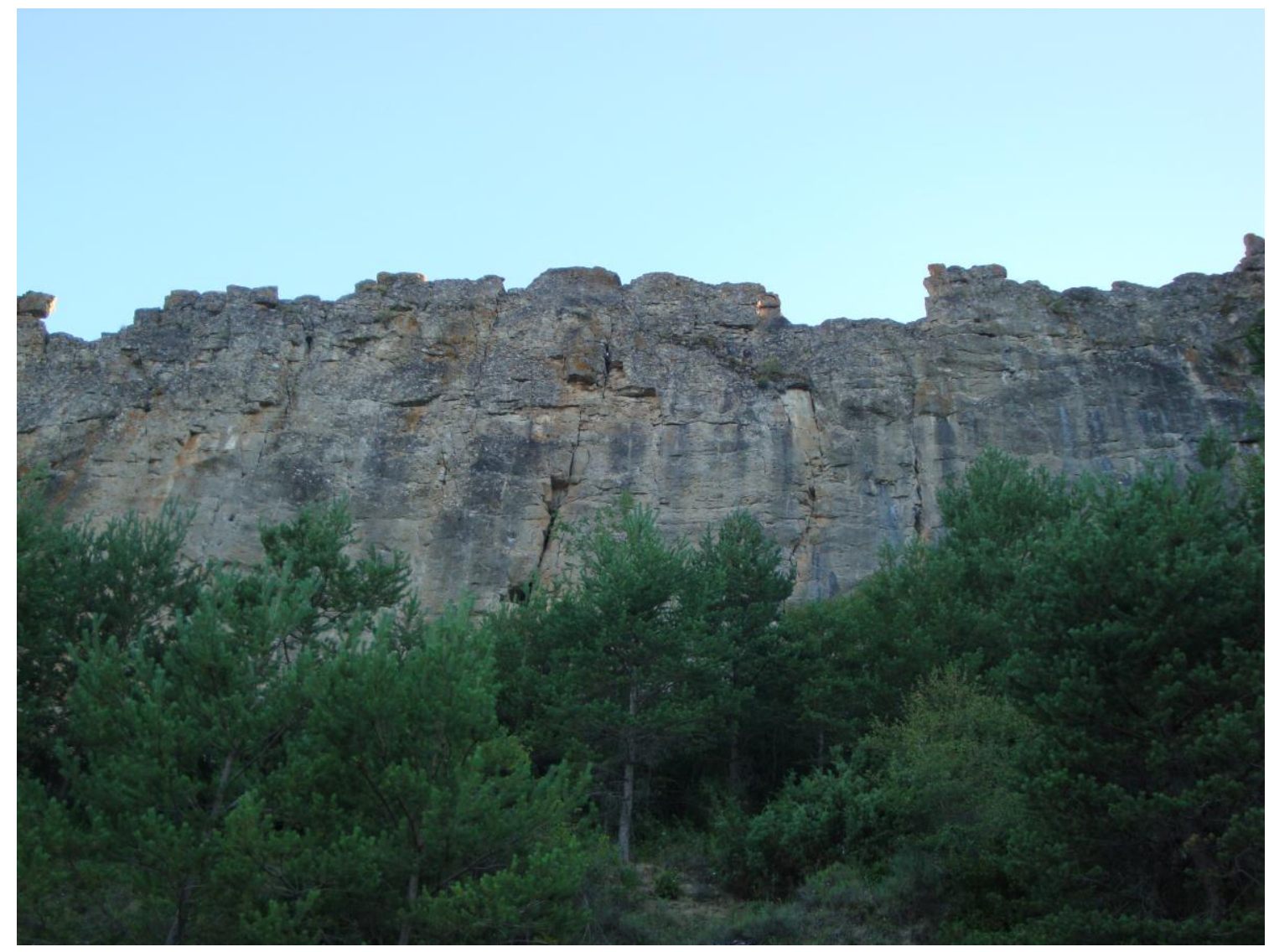

Un aspecto de las Rallas de Raspún

En la portada de este itinerario, ya se ha situado otra fotografía de las mismas

PARADA 2. CANTERA DE ARTO, (Arto, término municipal de Sabiñánigo, comarca del Alto Gállego). (Hoja 210).

Después de realizar la parada anterior, cabe regresar a la carretera nacional $\mathrm{N}-$ 330, para continuar hacía el Sur. Después de llegar al Hostal de Ispiés, nos convendrá tomar la carretera de Caldearenas, por la derecha. Casi después de haberla tomado, seguiremos por la carretera local HU - V - 3011, que conduce a Navasa, iniciando así una nueva hijuela. Por esta carretera llegaremos pronto a Baragua e inmediatamente después a Arto. Poco después de este pueblecito, efectuaremos una nueva parada en una antigua cantera. Así, desde el inicio de la hijuela habremos recorrido unos 3,5 Km. Y unos 9 desde la parada anterior.

En este recorrido, habremos ido encontrando los materiales ya mencionados en la parada anterior. Estos materiales son fundamentalmente del cenozoico y forman parte del Pirineo en este sector. 
En este lugar habremos encontrado una antigua (y pequeña) explotación de los niveles de arenisca cenozoicos. En realidad se trata de niveles de calcarenitas o de areniscas calcáreas. Por lo que concierne a la cantera, cabe decir que es de muy pequeñas dimensiones. Los materiales extraídos en ella pudieron utilizarse para las construcciones de los pueblos cercanos.

Cabe decir que en cercano pueblo de Baragua ya hubo una cantera similar, que ha quedado reflejada en la toponimia de la zona, con el nombre de las canteras, en donde podría hacerse una parada complementaria.

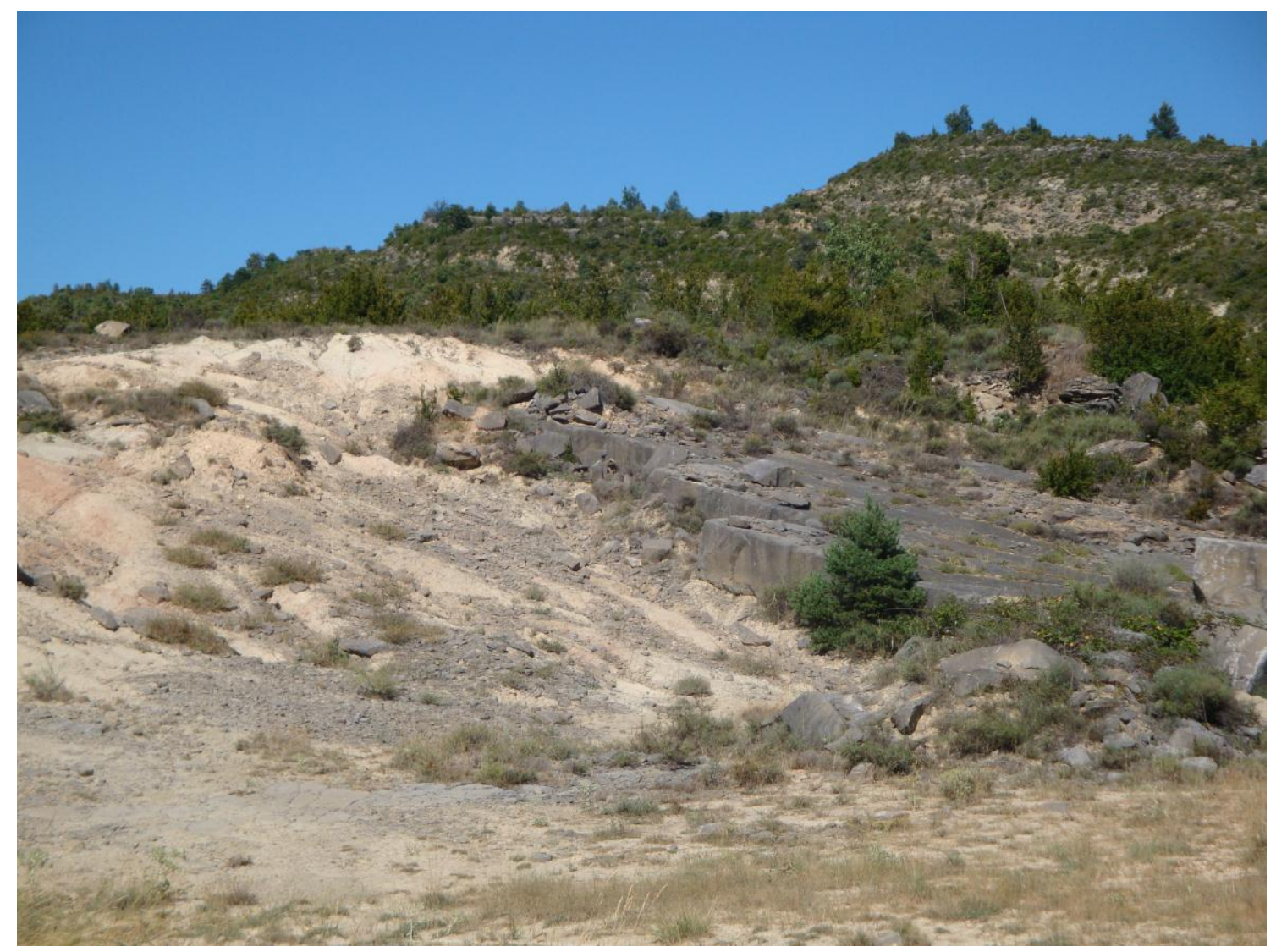

Restos de la antigua explotación

PARADA 3. GRAVERA DE HORNA DE GÁLLEGO, (Horna de Gállego, término municipal de Sabiñánigo, comarca del Alto Gállego). (Hoja 210).

Tras realizar la parada anterior, cabe deshacer la hijuela, retornando rápidamente hasta las inmediaciones de Baragua, para continuar hasta el poniente por la carretera local que se dirige hacía Caldearenas. A unos 1’1 Km después de haberla tomado de nuevo y a unos $4 \mathrm{Km}$ de la parada anterior, efectuaremos una nueva parada dentro del recorrido del presente itinerario.

En este tramo habremos ido encontrando los materiales mencionados en las paradas anteriores, pertenecientes al Cenozoico y formando parte del Pirineo Meridional, en donde continuamos situados. Estos materiales son fundamentalmente areniscosos, como 
los de la parada anterior. Precisamente, en este recorrido habremos pasado muy cerca del paraje de las Canteras, del que ya hemos hablado anteriormente.

Por otra parte, en este recorrido nos habremos acercado hasta el cauce actual del río Gállego, habiendo encontrado la terraza baja de este río. Precisamente, en el lugar de la parada ha habido una explotación de los materiales detríticos de la terraza baja, e incluso del propio cauce del río. En la actualidad esta gravera se halla cerrada y en buena parte inundada por las aguas del río.

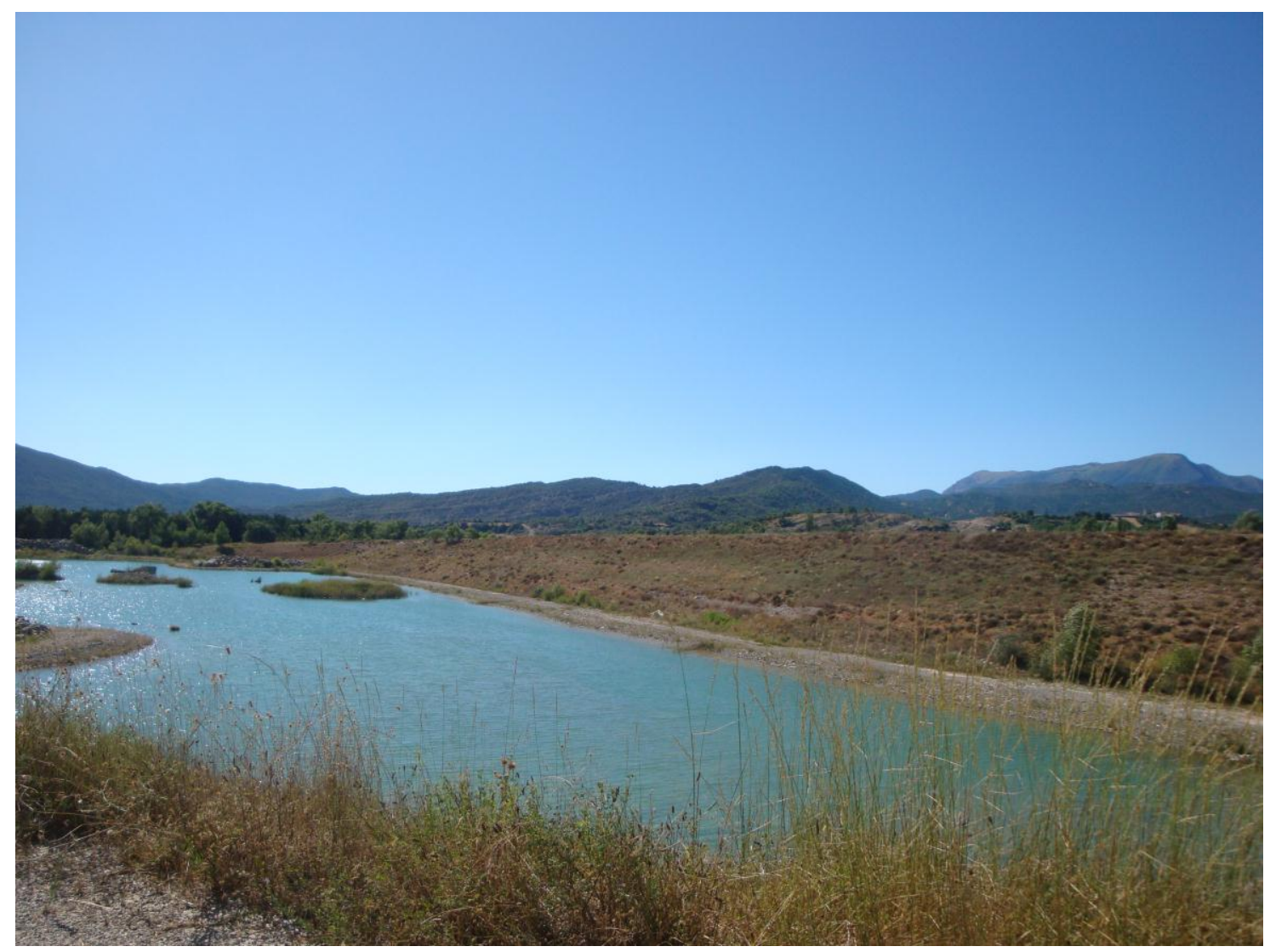

Aspecto actual de la gravera de Horna de Gállego

PARADA 4. EXPLOTACIONES DE LOSA DE SERUÉ, (Serué, término municipal de Caldearenas, comarca del Alto Gállego). (Hoja 210).

Después de realizar la parada anterior, cabe continuar por la carretera que conduce hacía Caldearenas. Así iremos pasando por las inmediaciones de Latras y poco después por Latres, llegando posteriormente a la capital del municipio, a Caldearenas. Tras ello será necesario continuar por la carretera que conduce a Bonrepós, pasando por Aquilué y posteriormente por San Vicente. Posteriormente llegaremos a la población de Serué, cerca de la actual realizaremos una nueva parada, tras recorrer unos $15 \mathrm{Km}$, desde la parada anteriormente realizada.

En este largo recorrido, hemos ido encontrando afloramientos de los materiales mencionados en las paradas anteriores, pertenecientes al Cenozoico. Como ya se ha dicho 
anteriormente, estos materiales forman parte de las estructuras pirenaicas en los presentes sectores del Pirineo Meridional.

Estos son también los materiales que aparecen en el lugar de la parada, los cuales han sido explotados en distintos lugares, como en las cercanías. Estos materiales han sido utilizados para la construcción de las casas. Estos materiales presentan características arenosas.

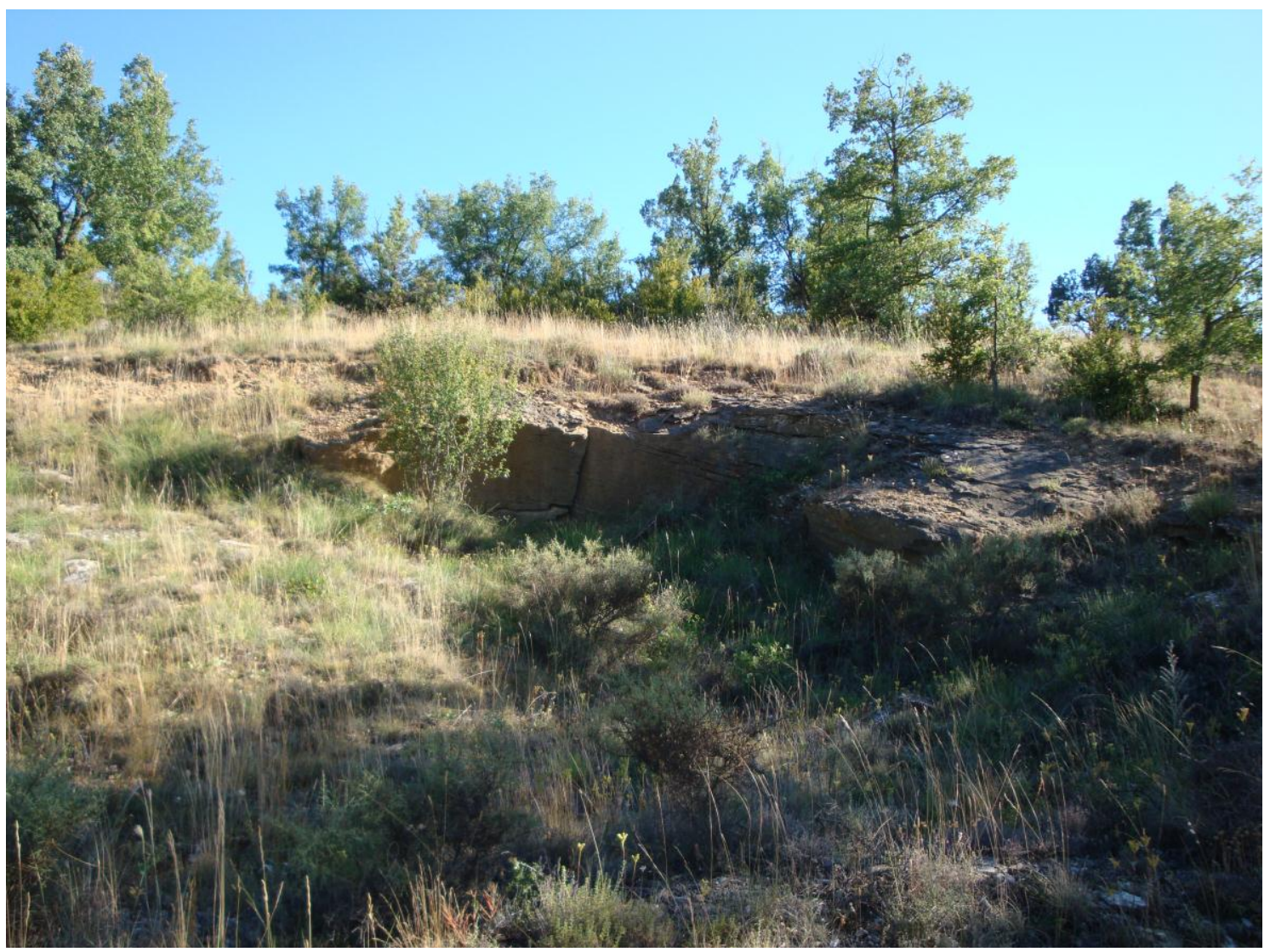

Detalle de una de las explotaciones

\section{PARADA 5. ANTENA DE TELÉFONOS DE BONREPÓS, (Casas de Bonrepós, término de Caldearenas, comarca del Alto Gállego). (Hoja 210).}

Tras realizar la parada anterior, cabe continuar por la carretera local que se dirige a Bonrepós (en realidad a la carretera nacional $\mathrm{N}-330$ ). En este recorrido pasaremos por el deshabitado de Escusaguas. Luego llegaremos hasta la carretera $\mathrm{N}-330$, por la que continuaremos brevemente hasta las cercanías del Puerto de Bonrepós, yendo hacía el Sur. Al llegar al puerto, nos podemos dirigir hacía la antena de teléfonos, en donde haremos una nueva parada, aunque la podríamos hacer en el mismo puerto. Así, desde la parada anterior, habremos recorrido unos $8 \mathrm{Km}$ más.

En este recorrido habremos ido encontrando afloramientos de los materiales mencionados en las paradas anteriores. Estos materiales, pertenecientes al Cenozoico, son los que afloran por los sectores en donde estamos ahora situados. Estos materiales pertenecen al denominado Pirineo Meridional. Fundamentalmente están constituidos por 
niveles de areniscas y de calcolutitas. Las areniscas son fundamentalmente calcarenitas, similares a las de la parada anterior.

Desde este lugar, mirando hacía el poniente y hacía el Norte, puede gozarse de un extraordinario punto de mira, de amplios sectores del Pirineo Meridional, en donde estamos situados desde el inicio del recorrido.

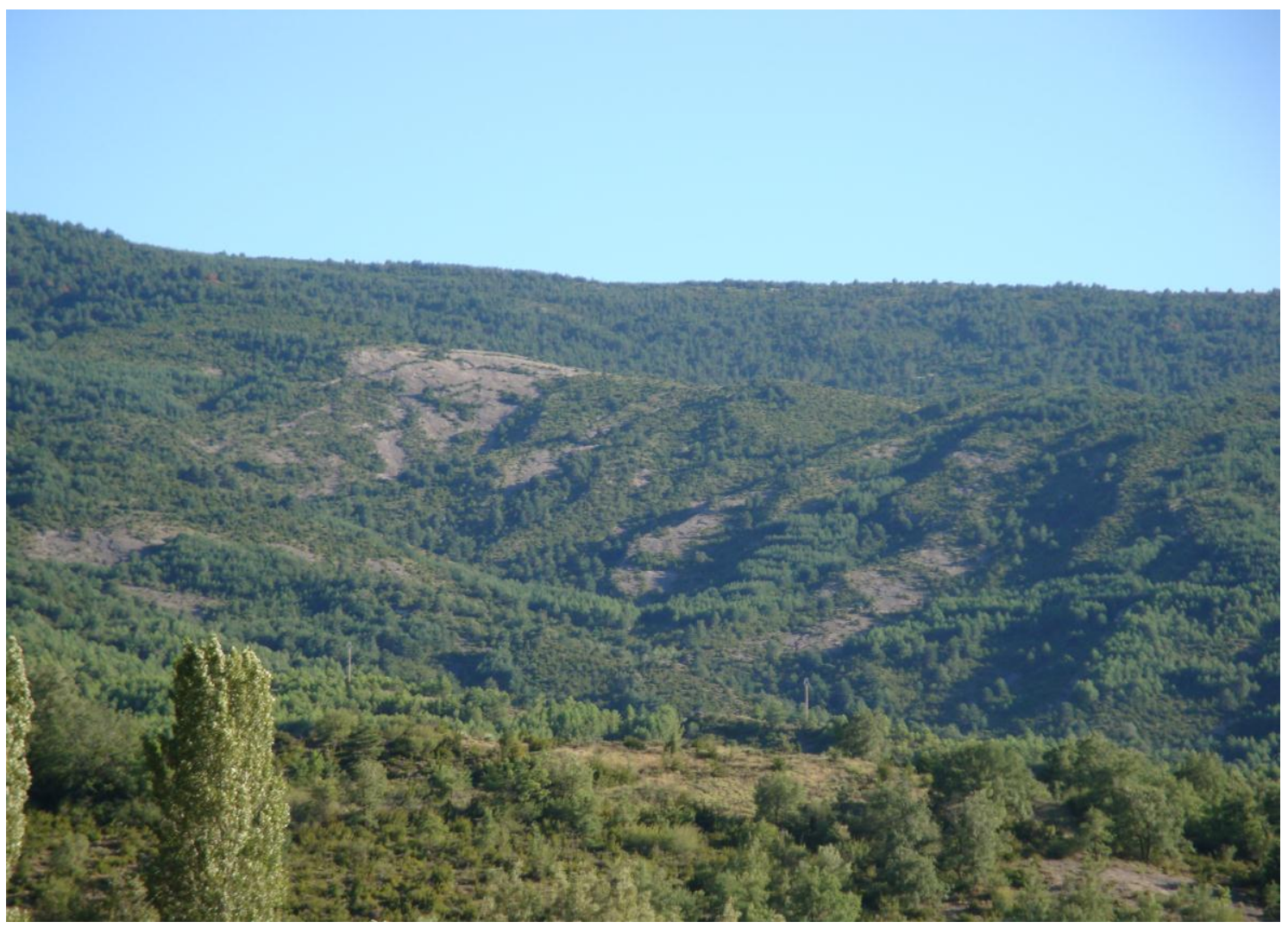

Detalle de los afloramientos de las calcarenitas, cerca de Bonrepós

PARADA 6. INMEDIACIONES DEL MOLINO DE VILLOBÁS, (Gésera, término municipal de Sabiñánigo, comarca del Alto Gállego). (Hoja 210).

Después de realizar la parada anterior, cabe retornar a la carretera nacional $\mathrm{N}$ 330, por la que ahora continuaremos hacía el Norte. Así, tras el sobrepasar el cruce de Caldearenas (por donde nosotros hemos llegado). Luego, continuando hacía el Norte, pasaremos por las inmediaciones de Alavés, continuando siempre hacía el Norte. Más adelante, en las cercanías del Hostal de Ispiés. Sin embargo, antes de llegar a él, encontraremos una carretera por la derecha. Se trata de la carretera autonómica A - 1604, por la cual continuaremos hacía el levante. Por ella, encontraremos los cruces de las cercanas poblaciones de Ordovés (hacía el Norte) y Arraso (hacía el Sur). Luego encontraremos el desvío de Gçsera llegando posteriormente al Molino de Villobás. Poco antes de llegar a él, haremos una nueva parada, a unos $15 \mathrm{Km}$ de la anterior.

En este recorrido, habremos ido encontrando afloramientos de los materiales cenozoicos mencionados anteriormente. Debajo de los anteriores se hacen patentes unos tramos rojizos, abundantes en calcarenitas y en areniscas. 
En este lugar es posible ver un interesante pliegue situado al lado de la carretera. Este pliegue ha dado lugar a un cabalgamiento, muy visible desde la carretera en donde ahora nos encontramos situados.

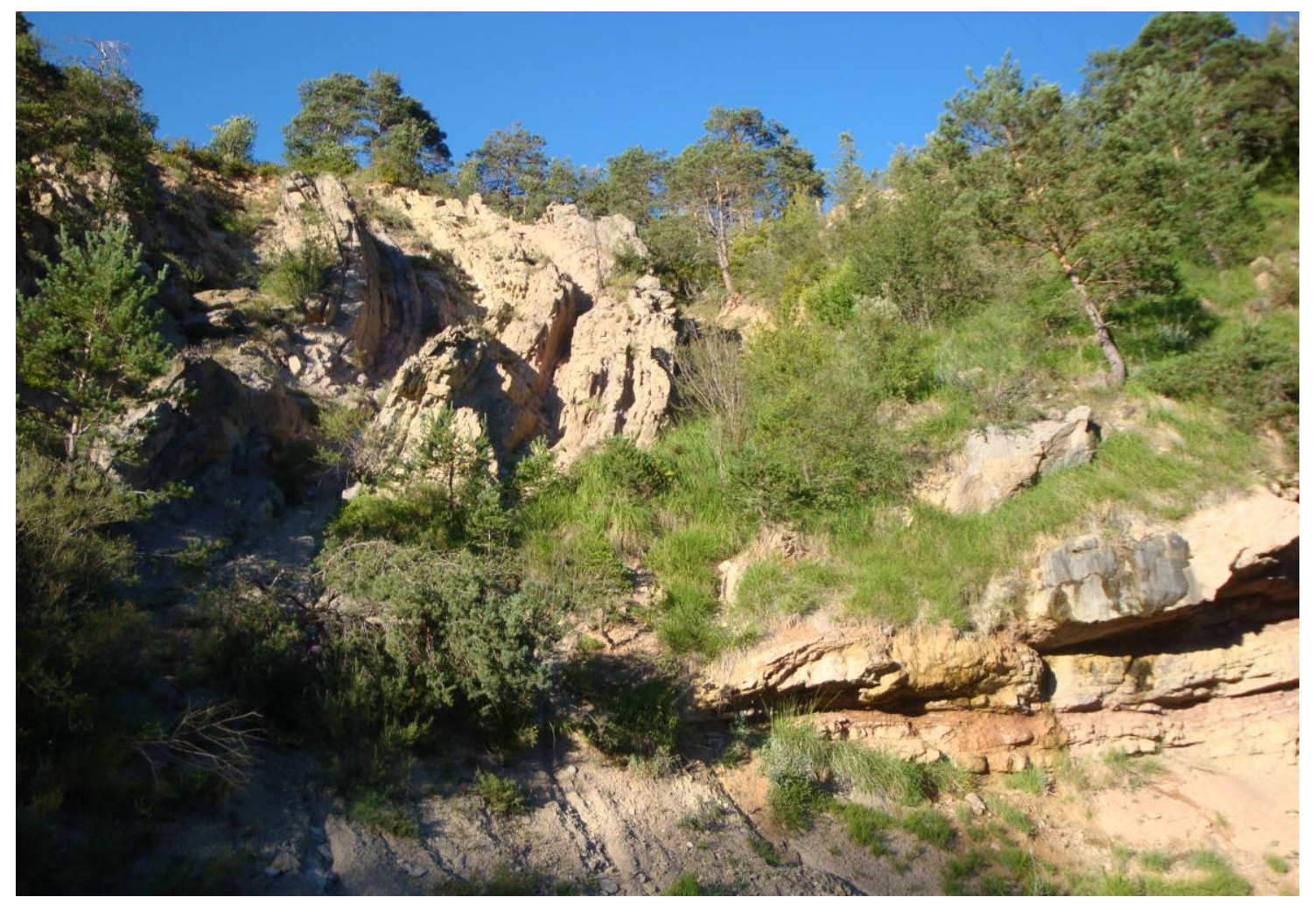

Un aspecto del pliegue y del cabalgamiento

\section{EN ESTE LUGAR FINALIZA EL RECORRIDO}

\section{BIBLIOGRAFIA}

CALVO, M. et altri (1988).- Minerales de Aragón. Colección: temas geológicos, Edit. Mira, 210 pag. Zaragoza

GADMA. (2001).- Puntos de Interés Geológico de Aragón, Edit. Gobierno de Aragón, Departamento de Medio Ambiente (GADMA). 243 pag. Zaragoza

MAESTRE, A. (1845).- Descripción geognóstica del Distrito Minero de Aragón y Cataluña. Anales de Minas, t. III, Madrid

MATA-PERELLÓ, J.M. (1987).- Introducción al conocimiento de las mineralizaciones aragonesas. Mineralogistes de Catalunya, t.III, pp. 258-265. Barcelona

MATA-PERELLÓ, J.M. (1990).- Inventario Mineralógico de la comarca del Sarrablo. Rodeno, $\mathrm{n}^{\circ}$ 16. 20 pag. Manresa

PRAMES (2005).- Alto Gállego. Colección RUTASCAL por Aragón. Prames, Gobierno de Aragón. 119 pag. Zaragoza. 